\title{
'NE-EDR sh2': A Yellow shrunken2 Sweet Corn Population with Disease Resistance from Exotic Sources
}

\author{
B.T. Scully ${ }^{1}$ \\ Everglades Research and Education Center, IFAS, University of Florida, \\ 3200 Old Palm Beach Road, Belle Glade, FL 33430-8003
}

\author{
J.L. Brewbaker ${ }^{2}$ \\ Department of Horticulture, University of Hawaii, 3190 Maile Way, Honolulu, \\ HI 96822
}

\author{
J.K. Pataky \\ Department of Crop Science, University of Illinois at Urbana-Champaign, \\ 1102 South Goodwin Avenue, Urbana, IL 61801-4798
}

\author{
W.F. Tracy ${ }^{4}$ \\ Department of Agronomy, University of Wisconsin, 1575 Linden Drive, \\ Madison, WI 53706-1590
}

\author{
M.E. Smith ${ }^{5}$ \\ Department of Plant Breeding and Biometry, Cornell University, 252 Emerson \\ Hall, Ithaca, NY 14853-1902
}

Additional index words. Zea mays, sugaryl gene, backcross breeding

Canada and the United States are presently the largest consumers, producers and exporters of sweet corn (Zea mays L.). Annual U.S production ranges from 200,000 to 250,000 ha, and among the vegetables sweet corn is only surpassed in production and consumption by tomatoes (Lycopersicon esculentum L.) (Tracy, 1994). In the last 25 years, large and organized sweet corn industries have become established in Europe, Australia, and New Zealand. Markets continue to emerge and develop in Asia, Latin America, the Middle East, and southern Africa. Much of this success is attributed to the increased shelf life and elevated sugar levels conferred by the shrunken 2 (sh2) gene (Mains, 1949), which has replaced the sugaryl (su1) allele over the last two decades (Kaukis and Davis, 1986). Additionally, U.S seed companies have aggressively expanded to create and meet this worldwide market demand. Although information regarding

\footnotetext{
Received for publication 27 Oct. 2000. Accepted for publication 14 May 2001. Florida Agricultural Experiment Station Journal Series No. R-07567. The cost of publishing this paper was defrayed in part by the payment of page charges. This research was supported by the NE-124 Regional Hatch Project. Under postal regulations, this paper therefore must be hereby marked advertisement solely to indicate this fact.

${ }^{1}$ Associate Professor, Plant Breeding and Genetics. To whom requests for reprints should be addressed. E-mail address: brts@gnv.ifas.ufl.edu

${ }^{2}$ Professor, Plant Breeding and Genetics. ${ }^{3}$ Professor, Plant Pathology.

${ }^{4}$ Professor, Plant Breeding and Genetics.

${ }^{5}$ Associate Professor, Plant Breeding.
}

market share and genetic origin of hybrids is privately held, it is commonly accepted that U.S seed companies and their cooperators or subsidiaries clearly dominate the world sweet corn seed industry. Regardless of market dominance, this seed industry is built upon an attenuated genetic base, derived primarily from New England and Midwestern germplasm (Gerdes et al., 1993; Kaukis and Davis, 1986). Most sweet corn hybrids are well adapted to the North American climate and to input levels commensurate with North American agricultural practices.

If U.S. seed companies are to continue their market expansion, new and novel genetic resources must be integrated into the germplasm base. Sweet corn needs to be more broadly adapted, particularly to tropical and subtropical climates; it must also have resistance to diseases and/or races uncommon or absent in North America. Current sources of monogenic resistance to many of the corn diseases are not highly effective in regions with racially diverse pathogen populations. In North America, monogenic resistance can break down as evidenced by the recent failure of the common rust (Puccinia sorghi Schw.) resistant $R p 1 d$ allele in the midwestern United States (Pataky and Tracy, 1999). Thus, it is clearly advantageous to have a working germplasm base with improved levels of polygenic resistance, which is less likely to select for virulence in the pathogen population. The purpose of this breeding program was to develop a yellow $s h 2$ population with disease resistance derived from exotic sources with specific focus on common rust and northern corn leaf blight [Exserohilum turcicum (Pass.)
Leonard \& Suggs] (NCLB), and evaluated across an expanded climatic range. Inbreds derived from this population could likely provide breeders with a source of polygenic disease resistance and another tactic to accompany monogenic/oligogenic resistance, such as recently developed by Hulbert and Drake (2000).

\section{Origin}

The NE-EDR $s h 2$ was developed in two phases that included recurrent mass selection (RMS) followed by a backcross procedure to introduce the recessive $s h 2$ allele into an open pollinated population. The original NE-EDR composite was assembled during Summer 1976 in Waimanalo, Hawaii; the NE is an abbreviation for the NE-124 Regional Hatch Project and the EDR is the exotic disease resistance supplied by the tropical germplasm. It included the following North American sul hybrids: 'Bonanza', 'Gold Winner', 'Golden Cross Bantam', 'Iobelle', 'Jubilee', 'Midway', 'NK 51036', 'Silver Queen', 'Stylepack', and the Hawaiian hybrid 'H 68' (Brewbaker, 1968), which were added to the composite on the basis of ear and horticultural quality. Also incorporated into the original composite were an open-pollinated cultivar, 'Haw'n Sugar'; a synthetic cultivar, Hisu1SYN. 2; and 10 disease-resistant composites of tropical origin, including HSX COMPS. 1, 6, 7, 8, 9, 10, and 11, along with o2-sul COMP. 1, 2, and 3 (Brewbaker, 1998; Gerdes et al., 1993). Each of these tropical entries was developed in Hawaii by recurrent mass selection with the objective of improving resistance to a broad spectrum of foliar diseases with either a sul or brittle1 (bt1) endosperm (Brewbaker, 1996, 1998). In the parental generation, each temperate hybrid was randomly assigned as a male to groups of three tropical females clustered in all possible permutations. The intent was to further deploy broad spectrum disease resistance from exotic tropical sources into U.S. sweet corn germplasm, specifically in a sul background.

After 11 cycles of RMS, the sh2 gene was introgressed into the NE-EDR sul in Hawaii and Florida. In Hawaii, version " $i$ " (9th cycle RMS) of the NE-EDR sul was used as the recurrent parent through to $\mathrm{BC}_{2} \mathrm{~F}_{2}$ when breeding line UH 93-824 was identified. The $\mathrm{BC}_{2} \mathrm{~F}_{3}$ was produced in Florida and version " $k$ " (11th cycle RMS) (UH96-923) of the NEEDR replaced version " $i$ " as the recurrent parent. The $\mathrm{BC}_{3}$ generation was consecutively backcrossed without selection to produce the $\mathrm{BC}_{4}$ generation. An isolated open pollination (IOP) of $\approx 125 \mathrm{BC}_{4}$ individuals was grown to recover the $s h 2$ genotype. Four IOP generations were grown after the $\mathrm{BC}_{5}$ generation. In the first IOP, selection was practiced for $s h 2$ kernels with yellow endosperm and in the second IOP selection focused on horticultural type, yellow endosperm, resistance to northern corn leaf blight and common rust. Progeny selected from this generation were evaluated for resis- 
tance to foliar diseases. The fourth increase was produced in the greenhouse for release.

\section{Description}

The second IOP generation after $\mathrm{BC}_{5}$ was distributed and rated in 1998 for rust resistance at five locations in Florida, Illinois, New York, Wisconsin, and Hawaii, where virulence occurs against the Rpld gene (Table 1). All versions of the NE-EDR populations were significantly more resistant to common rust than 'Florida Staysweet' or 'Supersweet Jubilee', the susceptible checks of North American origin. The NE-EDR populations were significantly less resistant to common rust than the Hawaiian hybrid 'Waimanalo Supersweet'. Among the populations, the sul versions were more resistant to rust than the $s h 2$ NE-EDR. In Florida, Illinois, and New York, resistance to northern corn leaf blight (NCLB) (Table 1) was also assessed and the North American hybrids were not significantly more susceptible than the tropical NE-EDR populations. 'Waimanalo Supersweet' was the most resistant to NCLB (Table 1). In Florida, the NE-EDR $s h 2$ plants ranged from 190 to $230 \mathrm{~cm}$ in height with an average of $206 \mathrm{~cm}$. Stalks had a basal diameter of 1.6 to $2.4 \mathrm{~cm}, 11$ to 14 nodes and light green brace roots. Tillers were mostly absent. The sul ver. $k$ parent ranged from 198 to $215 \mathrm{~cm}$ and averaged 207 $\mathrm{cm}$ in height on stalks with 11 to 14 nodes, a basal diameter of 1.8 to $2.2 \mathrm{~cm}$, light tan to yellowish green brace roots, and no tillers. The sul versions had the top ear expressed at heights of 46 to $70 \mathrm{~cm}$, averaged $62 \mathrm{~cm}$ and held angles from $15^{\circ}$ to $30^{\circ}$ from vertical. The $s h 2$ version had the top ear expressed at an average of $60 \mathrm{~cm}$, ranged from 40 to $85 \mathrm{~cm}$, and held ears at $15^{\circ}$ to $20^{\circ}$ from vertical. The standard hybrids, 'Florida Staysweet' and 'Supersweet Jubilee' were both shorter in plant height by at least $30 \mathrm{~cm}$, had two to four fewer nodes, a narrower basal diameter and fewer brace roots. As expected, these hybrids were more uniform than either NE-EDR population.

The sh2 NE-EDR had four to six leaves above the ear, while the $s u l$ version had five to seven. At silking, the sh2 version had 10 to 12 leaves compared to 11 to 13 for the sul population. At the top ear node, leaves ranged from 53 to $79 \mathrm{~cm}$ in length, and 9.1 to $12.2 \mathrm{~cm}$ in width, with 2 to 5 undulations of amplitudes between 2.0 and $3.0 \mathrm{~cm}$. The sul NE-EDR had leaves that ranged from 71 to $86 \mathrm{~cm}$ in length and 9.5 to $11.4 \mathrm{~cm}$ in width, with 4 to 7 undulations of 2.5 to $3.8 \mathrm{~cm}$ in amplitude. These leaf dimensions were similar to 'Florida Staysweet' and 'Waimanolo Supersweet'; 'Jubilee' had leaves that averaged 5 to $10 \mathrm{~cm}$ shorter and 2 to $3 \mathrm{~cm}$ narrower. The ear leaves were generally held at angles of $45^{\circ}$ to $60^{\circ}$ from vertical on the $s h 2$ population and less upright angles for the sul population. Leaves were distally pendulant for both populations. The top ear node ranged from 12.0 to $17.4 \mathrm{~cm}$ in length and 1.1 to $1.8 \mathrm{~cm}$ in width on the $s h 2$ NE-EDR, and from 13.5 to $19.0 \mathrm{~cm}$ and 1.6 to $2.6 \mathrm{~cm}$, respectively on the sul versions.

Table 1. Comparison of mean ( $\pm \mathrm{SE}$ ) ratings for resistance to common rust (Puccinia sorghi Schw.) evaluated in Florida, Illinois, Hawaii, New York, and Wisconsin, and northern corn leaf blight (NCLB) [Exserohilum turcicum (Pass.) Leonard \& Suggs] rated in Florida, Illinois and New York in 1998

\begin{tabular}{lcc}
\hline \hline Hybrid/Population & Common rust mean \pm SE & NCLB mean \pm SE \\
\hline 'Florida Staysweet' & $6.5 \pm 0.8$ & $3.2 \pm 0.2$ \\
'Supersweet Jubilee' & $4.2 \pm 1.0$ & $2.6 \pm 0.4$ \\
NE-EDR $s h 2$ & $2.6 \pm 0.3$ & $2.3 \pm 0.7$ \\
NE-EDR $s u 1$ ver. $k$ & $2.5 \pm 0.3$ & $1.8 \pm 0.3$ \\
NE-EDR $s u l$ ver. $i$ & $1.7 \pm 0.4$ & $1.7 \pm 0.2$ \\
'Waimanalo Supersweet' & $0.7 \pm 0.3$ & $1.2 \pm 0.3$ \\
$\mathrm{P}_{\alpha=0.05}$ & 0.8 & 0.7
\end{tabular}

${ }^{2}$ Diseases were rated on a 0 to 9 scale, with 0 for resistance and 9 for very heavy infection.

All sites, with the exception of Illinois, relied on natural infection.

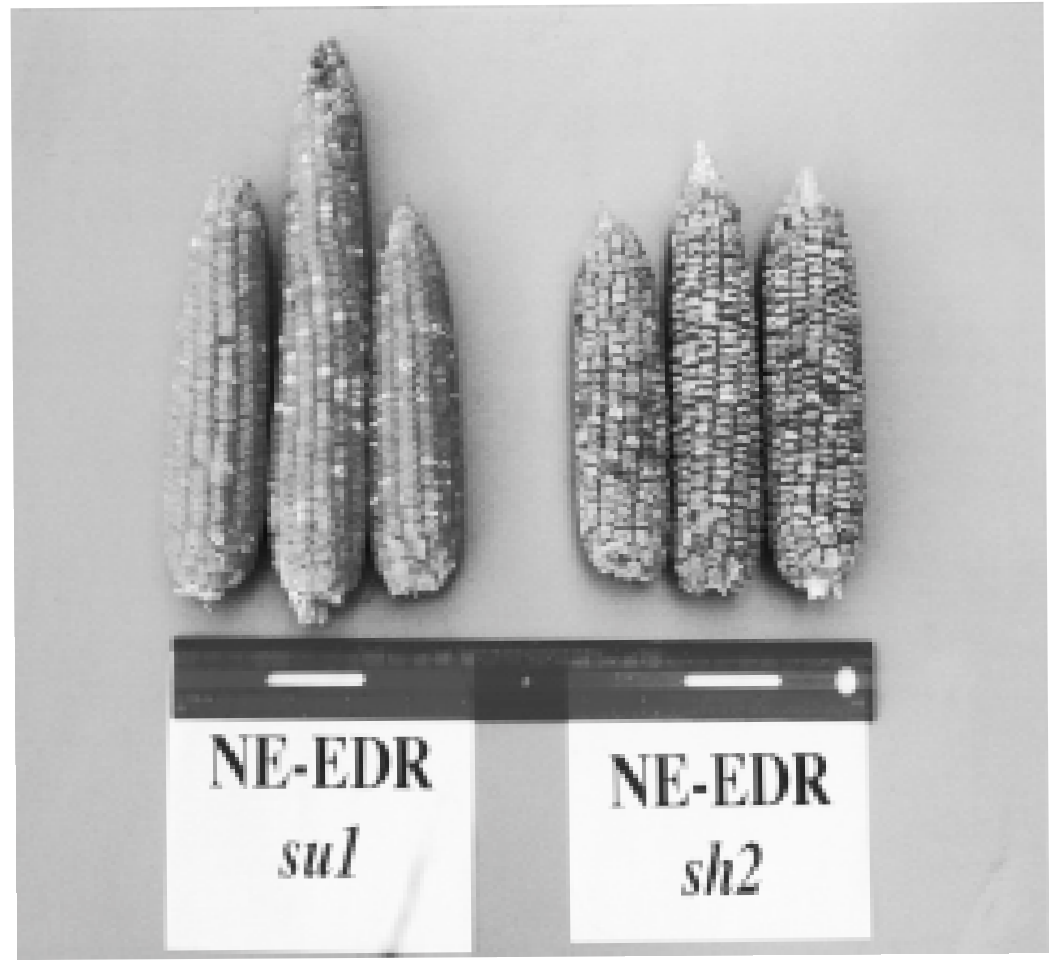

Fig. 1. Ears of the NE-EDR sh2 and sul populations.

Ears had shanks of 6.7 to $13.5 \mathrm{~cm}$ and 7.2 to $18.5 \mathrm{~cm}$ for the $s h 2$, sul populations, respectively. Ears on the NE-EDR sh2 had 9 to 14 husks, and attached to shanks with seven to nine nodes; the sul populations had up to 19 husk leaves and up to 14 nodes per shank. Husk leaves commonly averaged $22.0 \mathrm{~cm}$ in length and $10.5 \mathrm{~cm}$ in width for the NE-EDR $\operatorname{sh} 2$; the sul versions had average husk lengths of 23.0 $\mathrm{cm}$ and $9.7 \mathrm{~cm}$ widths. Husk flag leaves of 1.0 to 5.0 are formed on about $20 \%$ of the NE-EDR $s h 2$, while the $s u 1$ versions produced flag leaves up to $15.0 \mathrm{~cm}$ on $35 \%$ of the husks. For both populations, less than five or six husks expressed flag leaves. Husk extension beyond the ear tip ranged from 2.5 to $4.0 \mathrm{~cm}$ on $s h 2$ population and 7.2 to $18.5 \mathrm{~cm}$ on the $s u l$ version. On both populations, very light green to tan silk extruded from the husk tip 4.0 to $8.0 \mathrm{~cm}$. A reddish hue was occasionally visible on the $s u 1$ population.

Cobs of both populations are off-white to cream colored and weak with about a $1.1-\mathrm{cm}$ core diameter and a round transect. Husked and dry ears of the $s h 2$ population ranged in length from 10.0 to $20.0 \mathrm{~cm}$ and averaged $13.2 \mathrm{~cm}$ with an average diameter of $3.9 \mathrm{~cm}$. Blanked ear tips up to $1.0 \mathrm{~cm}$ occurred on $30 \%$ of the ears in Florida. Fourteen and 16 rowed ears represent about two-thirds of sh2 population. The sul population had ears that averaged $13.5 \mathrm{~cm}$ in length and $4.0 \mathrm{~cm}$ in width. Tips blanked on $25 \%$ of these ears with an average unfilled portion of $1.0 \mathrm{~cm}$. Nearly $25 \%$ of the ears had 14 rows, while the ears with 12 and 16 rows represented $15 \%$ each. Kernel shape and dimension is variable for both of these populations (Fig. 1).

Tassels of the $s h 2$ NE-EDR have yellow anthers and light green glumes. The central spike ranges in length from $17.0 \mathrm{~m}$ to $24.0 \mathrm{~cm}$ with a median length of $22.0 \mathrm{~cm}$ and a spike width that varies from 7.0 to $11.0 \mathrm{~mm}$. Commonly this population has 9 to 19 secondary branches held at an average of $45^{\circ}$ from verti$\mathrm{cal}$, and up to three tertiary branches. These secondary tassel branches range in length from 10.0 to $24.0 \mathrm{~cm}$ and have widths of $\approx 7.0 \mathrm{~mm}$. 
Tassels are borne on peduncles that range from 17.0 to $29.0 \mathrm{~cm}$ with roughly $60 \%$ of this node enveloped by the sheath of the top leaf. Pollen shed is moderate to heavy. Compared to the $s h 2$ version, the sul population tends to have a heavier pollen flow, tassel morphology enlarged by 10 to $15 \%$, branches held closer to vertical, with anther and glume colors that are deeper green with an occasional reddish hue.

\section{Availability}

Seed samples of this population are freely available from B.T.S. Seed has also been deposited into the U.S. Dept. of Agriculture, National Seed Storage Laboratory (NSSL), at
Fort Collins, Colo., on 8 Nov. 2000, and assigned the number PI 614830.

\section{Literature Cited}

Brewbaker, J.L. 1968. 'Hawaii H38' and 'Hawai H68': Hawaiian sweet corn hybrids. Circ. No. 66. College of Trop. Agr. and Human Resources, Univ. of Hawaii, Honolulu.

Brewbaker, J.L. 1996. Corn production in Hawaii. College of Trop. Agr. and Human Resources, Univ. of Hawaii, Honolulu.

Brewbaker, J.L. 1998. Disease resistant tropical supersweet corn populations. HortScience 33:1262-1264.

Gerdes, J.T., C.F. Behr, J.G. Coors, and W.F. Tracy. 1993. Compilation of North American maize breeding germplasm. Crop Sci. Soc. Amer., Madison, Wis.
Kaukis, K. and D.W. Davis. 1986. Sweet corn breeding, p. 477-512. In: Breeding vegetable crops, M.J. Bassett (ed.). AVI Publishing, Westport, Conn.

Hulbert, S.H. and J.A. Drake. 2000. Rust-resistant sh 2 sweet corn populations. HortScience 35:145146.

Mains, E.B. 1949. Hereditable characters in maize: Linkage of a factor for shrunken endosperm with the $a 1$ factor for aluerone color. J. Hered. 40:21-24.

Pataky, J.K. and W.F. Tracy. 1999. Widespread occurrence of common rust, caused by Puccinia sorghi, on $R p$ resistant sweet corn hybrids in the midwestern U.S. Plant Dis. 83:117.

Tracy, W.F. 1994. Sweet corn, p. 155-197. In: Speciality Corns (2nd ed.). A.R. Hallauer (ed.). CRC Press, Boca Raton. 